\title{
Nursing Theory and Its Practices in Two Health Care Facilities of Bujumbura
}

\author{
Emmanuel Gasaba1, Bosco Ntiranyibagira1, Iranyishuye Joseph11, Thérèse Uwamariya1, \\ Emmanuel Nkurikiye1, Pierre Hategekimana', Emmanuel Ndarusanze', Edouard Niyongabo ${ }^{2,3^{*}}$
}

${ }^{1}$ Faculty of Health Sciences, Hope Africa University, Bujumbura, Burundi

${ }^{2}$ Hope Africa University, Bujumbura, Burundi

${ }^{3}$ Department of Public Health Sciences, National Institute of Public Health, Bujumbura, Burundi

Email: *niyongaboedouard@gmail.com

How to cite this paper: Gasaba, E., Ntiranyibagira, B., Joseph, I., Uwamariya, T., Nkurikiye, E., Hategekimana, P., Ndarusanze, E. and Niyongabo, E. (2021) Nursing Theory and Its Practices in Two Health Care Facilities of Bujumbura. Open Journal of Nursing, 11, 757-771.

https://doi.org/10.4236/ojn.2021.119064

Received: April 29, 2021

Accepted: September 21, 2021

Published: September 24, 2021

Copyright $\odot 2021$ by author(s) and Scientific Research Publishing Inc. This work is licensed under the Creative Commons Attribution International License (CC BY 4.0).

http://creativecommons.org/licenses/by/4.0/

\begin{abstract}
Introduction: Nursing theory provides a systematic explanation and description of nursing phenomena. It is very important during nursing practice in healthcare facilities (HCFs) because it guides nurses on how to collect data, which data to collect, decide how to interpret the data through the perspective of the theorist, how to plan and implement care, how to make a change and how to evaluate the patient's outcomes. This study aims to illustrate how nursing theory can be applied during the implementation of nursing care in HCFs of Burundi by orienting the nurses to understand its application during practice. Methods: A cross-sectional study design was used to assess the use of nursing theories in healthcare facilities. A purposive sampling method was used also to select 81 nurses working full and part by applying Alain Bouchard's formula and the questionnaire was used as the data collection instrument. Results: The current study had revealed a poor knowledge among the participants on the use of nursing theory in these two HCFs as for all variables, their average scores were almost $24.1 \%$ whilst those who had no notion related to nursing theory reach a percentage of $75.9 \%$. Conclusion: The study findings were slightly poor as for all variables, they scored less than $40 \%$. Therefore, the use of theories to guide their practice was highly recommended to enhance the patients' outcomes based on the use of scientific-based experts which could result from continuous education.
\end{abstract}

\section{Keywords}

Nursing, Nursing Theory, Nursing Practice, Healthcare Facilities (HCFs)

\section{Introduction}

Nursing has made the phenomenal accomplishment in the past era that has led 
to the credit of nursing as an educational discipline and a profession in contemporary nursing. A move towards theory-based practice has made modern nursing more expressive and significant by everchanging nursing's emphasis from vocation to an organized nursing profession. The stipulation for this knowledge-base to guide expert nursing practice had been standardized in the first half of the twentieth century and many hypothetical works have been supported by nurses repetitively from the time when first with the goal of making nursing a recognized profession and later with the aim of providing nursing care to patients as experts using this scientifical-based skill.

Nursing theory is an integrated set of concepts and statements that can be used to explain, describe, predict or control a phenomenon. It is very important during nursing practice in HCFs because it guides nurses on how to collect data, which data to collect, decide how to interpret the data through the perspective of the theorist, how to plan and implement care, how to make a change and how to evaluate the outcomes [1]. In addition, a theoretical perspective helps nurses to focus on the important and meaningful data which gives nurses a way to understand the data, to interpret the relationships among the phenomena, to plan and implement care purposefully and systematically. Nursing theories guide the way for nursing practice and provide a foundation for clinical decision making in $\mathrm{HCF}$, helps to generate further knowledge, and indicate in which direction nursing should develop in the future [2]. Whoever, without this understanding, data are often collected and left uninterested or never collected at all and nurses are very busy and have little time to spend on activities that do not convey specific meaning. When the theories are neglected, it would be impossible for providers to practice without an understanding of nursing theory because the majority of nurses will fail to conduct a good nursing process, especially in decision-making to the patient [3].

Developed countries like Australia, Belgium, Canada, Cyprus, United States, Finland, France, Ireland, Japan, Poland, Czech Republic and United Kingdom; the study carried out by the OECD (Organization for Economic Co-operation and Development) in those 12 countries for examining the experience based on nursing care showed that nursing skills were well oriented based on nursing theory because they have a greater experience related to the advanced nursing skills oriented to the nursing theories [4].

In a developing country like Kenya where resources setting is limited, the majority of nurses present a lack of knowledge of nursing theories and their use in their daily basis practice [5]. It is evident from literature that there is a gap between nursing theories for practice as taught in the classroom and actual nursing practice. Literature further suggests that the theories taught are inappropriate for practice in the African context [6].

In Burundi, no study has been carried out on the use of theories in HCFs. Therefore, this study needs to be conducted in order to illustrate how nursing theory can be applied during the implementation of nursing care in HCFs of Burundi and to orient the nurses to understand how to apply nursing theory 
during the nursing care in HCFs. In addition, it can provide the contribution for guiding the government on how to establish the policies for orienting the nursing care in HCFs. It could also reveal how the nursing theory could be important during nursing care in all HCFs of Burundi, especially in CVN and CHUK. Therefore, this study aims to assess the use of nursing theory, its importance during nursing practice in these two HCFs and how they can improve the nursing skills during their practice by using nursing theories.

\section{Theoretical Context}

Dorothea Orem's theory was chosen among others because it is the general theory of nursing. It delineates when nursing is required. This theory can be used by practitioners to guide and improve their practice. It provides a comprehensive foundation for nursing practice. It has great utility for an application to modern clinical practice and can be applied in most cases to achieve desired medical outcomes and care. It focuses on improving the patient's ability to self-care and expanding that capacity to care for their dependents. The steps of this approach are considered the technical component of the nursing process [7].

Another theory that has been chosen is the Nursing Process Theory of Ida Jean Orlando. She describes in her nursing process theory principles of effective interaction with the patient that lead to effective interventions and most likely to positive outcomes. It allows nurses to formulate an effective nursing care plan that can also be easily adapted when and if any complexity comes up with the patient because patients have their own meanings and interpretations of situations and therefore nurses must validate their inferences and analyses with patients before drawing conclusions. This process helps nurses to find out the nature of the patient's distress and provide the help he or she needs [8] (Table 1).

\section{Methods}

The study was conducted into two HCFs of Bujumbura: Van Norman Clinic (CVN) and University's Hospital Centre of Kamenge (CHUK) located in the North District of Bujumbura the capital city of Burundi in the urban commune of NTAHANGWA from November to December 2019. It was a descriptive study design. A cross-sectional study design was used to assess the use of nursing theories in these two HCFs by nurses. A purposive sampling method was used to select 81 nurses working full and part-time in five units (internal medicine, maternity, pediatric, surgical, and emergency units) of these two HCFs. All nurses who did not work in those five units, those who were on leave, trainees' nurses and those who were on professional placements, were excluded in our study. Alain Bouchard's formula was used to calculate this sample of 81 nurses. The formula was:

$$
N C=\frac{n}{1+\frac{n}{N}}
$$


Table 1. Characteristics of the chosen Theories.

\begin{tabular}{|c|c|c|}
\hline $\begin{array}{l}\text { Theory and } \\
\text { its author }\end{array}$ & Description of the theory & Contribution of the theory \\
\hline $\begin{array}{l}\text { Nursing } \\
\text { Process } \\
\text { Theory: } \\
\text { Ida Jean } \\
\text { Orlando }\end{array}$ & $\begin{array}{l}\text { Orlando came up with a nursing process with five steps: assessment, } \\
\text { diagnosis, planning, implementation, and evaluation. Assessment is } \\
\text { figuring out what the patient needs to be helped and is retrieved from the } \\
\text { patient's behavior. Diagnosis is the identification of what is needed for } \\
\text { that help. Planning is setting goals to relieve the patient's distress. } \\
\text { Implementation is the carrying out of the planned goals. And evaluation } \\
\text { is determining if the need is met and how effective it was [9]. } \\
\text { The nurse uses the standard nursing process in Orlando's Nursing } \\
\text { Process Discipline Theory, which follows: assessment, diagnosis, } \\
\text { planning, implementation, and evaluation. The theory focuses on the } \\
\text { interaction between the nurse and patient, perception validation, and the } \\
\text { use of the nursing process to produce positive outcomes or patient } \\
\text { improvement. Orlando's key focus was the definition of the function of } \\
\text { nursing. The model provides a framework for nursing, but the use of her } \\
\text { theory does not exclude nurses from using other nursing theories while } \\
\text { caring for natients } 110\end{array}$ & $\begin{array}{l}\text { Her goal was to contribute to concerns about } \\
\text { a) The nurse-patient relationship; } \\
\text { b) The nurse's professional role and identity; } \\
\text { c) Knowledge development distinct to nursing. } \\
\text { It allows nurses to formulate an effective nursing care plan } \\
\text { that can also be easily adapted when and if any complexity } \\
\text { comes up with the patient. According to her, persons } \\
\text { become patients requiring nursing care when they have } \\
\text { needs for help that cannot be met independently because } \\
\text { of their physical limitations, negative reactions to an } \\
\text { environment, or have an experience that prevents them } \\
\text { from communicating their needs. The role of the nurse is } \\
\text { to find out and meet the patient's immediate needs for help } \\
\text { [11]. }\end{array}$ \\
\hline
\end{tabular}

This model is essential to the field, as it provides the Dorothea Orem; is the theory of self-care deficit that is composed of three related theories:

Dorothea Elizabeth Orem's Self-Care Deficit theory
1) Personal care theory, describing how people take charge of themselves; 2) Self-care deficit theory, which explains why people can be helped through nursing;

3) The theory of nursing systems describing and explaining the relationships that need to be initiated and maintained for nursing to be produced. In this model of practice, the outcomes of all nursing action should be to promote self-care in all individuals [12]. profession with a guide to patient care and a general frame of reference that links the structural environment to the models of behavior and knowledge. It is useful for professional nurses in the areas of nursing practice; this approach to personal care is contemporary with the concepts of health promotion and health maintenance. This model undertakes to maintain life, health and well-being and will be applied to achieve three expected outcomes that can help prevent illness and promote health: improving client education; decreased levels of illness and disability; and an increased ability to make decisions about health [9].

Van Norman Clinic has the population of 55 nurses. By using Alain Bouchard's formula, the sample was 35 participants.

$$
N C=\frac{96}{1+\frac{96}{55}}=34.9 \sim 35 .
$$

CHUK has the population of 185 nurses. By using Alain Bouchard's formula, the sample was 46 participants.

$$
N C=\frac{96}{1+\frac{96}{185}}=45.4 \sim 46 .
$$

This is to make a total sample of 81 participants in this study.

We have considered those two HCFs (CVN and CHUK) because they were training HCFs centers that help students to practice advanced skills, assuming that also nurses who work in these latter were supposed to be qualified in nursing profession that's why the study has been conducted there to see if they integrate nursing theories into their nursing practice too.

The data were collected by using the questionnaire established based on five sections: demographic data, importance of nursing theory, baseline of nursing 
theory, implementing nursing theory into practice, Rational diagnosis of nursing theory.

A Statistical Package for Social Scientists version 16.0 software (SPSS) was used to analyze the data which were presented as a frequency tables, bar graphs. The score of the results were classified refer to the items' scored by participants in each section of variables. It was good for those who scored more than $50 \%$, it was medium for those whose score were between $40 \%$ and $50 \%$ and for those whose score were less than $40 \%$ was classified as poor. Ethical principles had been respected where an oral informed consent was given to participants and these latter were given a choice whether to participate in the survey or not and the authorization to carry out the study was required from the University re-search committee and the hospitals superintendents from these institutions.

\section{Results}

The findings revealed that the age of participants ranged between 23 years to 55 years $(\bar{x}=37.3)$. Majority of them were female $(60.5 \%)$ and $39.5 \%$ were man. Majority of the participant were nurses who work at CHUK (56.8\%) and 43.2\% were nurses who work at VNC. Most of them (50.6\%) have been in service for 3 to 5 years, while others have 1 to 2 years, 6 to 10 years and mor than 10 years (30.8\%, 13.6\% and 3.7\% respectively). Majority of the participant (53.1\%) have secondary level of nursing training while $43.2 \%$ and $3.7 \%$ have university level (Bachelor and Master level respectively). The participants were located in Surgical, Maternity, Internal medicine, Emergency and Pediatric Unit (14.8\%, 18.5\%, $32.1 \%, 8.6 \%, 26.0 \%$ respectively) in these two hospitals (Table 2 ).

Table 2. Distribution of demographic data of the participants.

\begin{tabular}{ccc}
\hline \multicolumn{2}{c}{ Characteristics } & Frequency $(\mathrm{N}=81)$ \\
\hline \multirow{2}{*}{ Age } & Range & $23-55$ years \\
& Mean & 37.3 years \\
& Male & $32(39.5 \%)$ \\
Institution & Female & $49(60.5 \%)$ \\
& VNC & $35(43.2 \%)$ \\
Period on service (Years) & CHUK & $46(56.8 \%)$ \\
& $1-2$ & $25(30.8 \%)$ \\
& $3-5$ & $41(50.6 \%)$ \\
Level of education & $6-10$ & $11(13.6 \%)$ \\
& More than10 & $4(5.0 \%)$ \\
& Diploma (A2) & $43(53.1 \%)$ \\
& BSN & $35(43.2 \%)$ \\
& MSN & $3(3.7 \%)$
\end{tabular}


Distribution of the Study Population according to Knowledge of Nursing Theory

The participants' knowledge of nursing theory was significant poor, $24.1 \%$ were the only ones who know nursing theory while majority of them did not have any idea of what is it (Figure 1).

Distribution of the Study Population according to the Importance of Nursing Theory

The participants knowledge on the importance of nursing theory was poor as for all variables, their scores were less than $34 \%$ (Table 3).

Distribution of the Study Population according to Baseline of Nursing Care

The current study revealed also a lack of knowledge on the steps related to the baseline of nursing care among the participant as for all variables the scores were less than $34 \%$, especialy that all participants disclaim to be guided by nursing theories during the implementation of nursing care (Figure 2).



Figure 1. Knowledge of nursing theory.

Table 3. Importance of nursing theory.

\begin{tabular}{ccc}
\hline \multicolumn{1}{c}{ Characteristics } & Frequency \\
\hline Know nursing theory & Yes & $33.9 \%$ \\
Description of Nursing theory & No & $66.1 \%$ \\
& Yes & $33.9 \%$ \\
Importance of nursing theory during practice. & No & $66.1 \%$ \\
Nursing knowledge based on nursing theory & Yes & $35.6 \%$ \\
Nursing practice based on nursing theory & No & $64.4 \%$ \\
& Yes & $32.2 \%$ \\
Rational nursing diagnosis based on theory & No & $67.8 \%$ \\
& Yes & $32.2 \%$ \\
Help to generate new knowledge in nursing & No & $67.8 \%$ \\
& Yes & $32.2 \%$ \\
Difficult to provide nursing care without nursing theories & No & $67.8 \%$ \\
& Yes & $32.2 \%$ \\
& No & $67.8 \%$
\end{tabular}




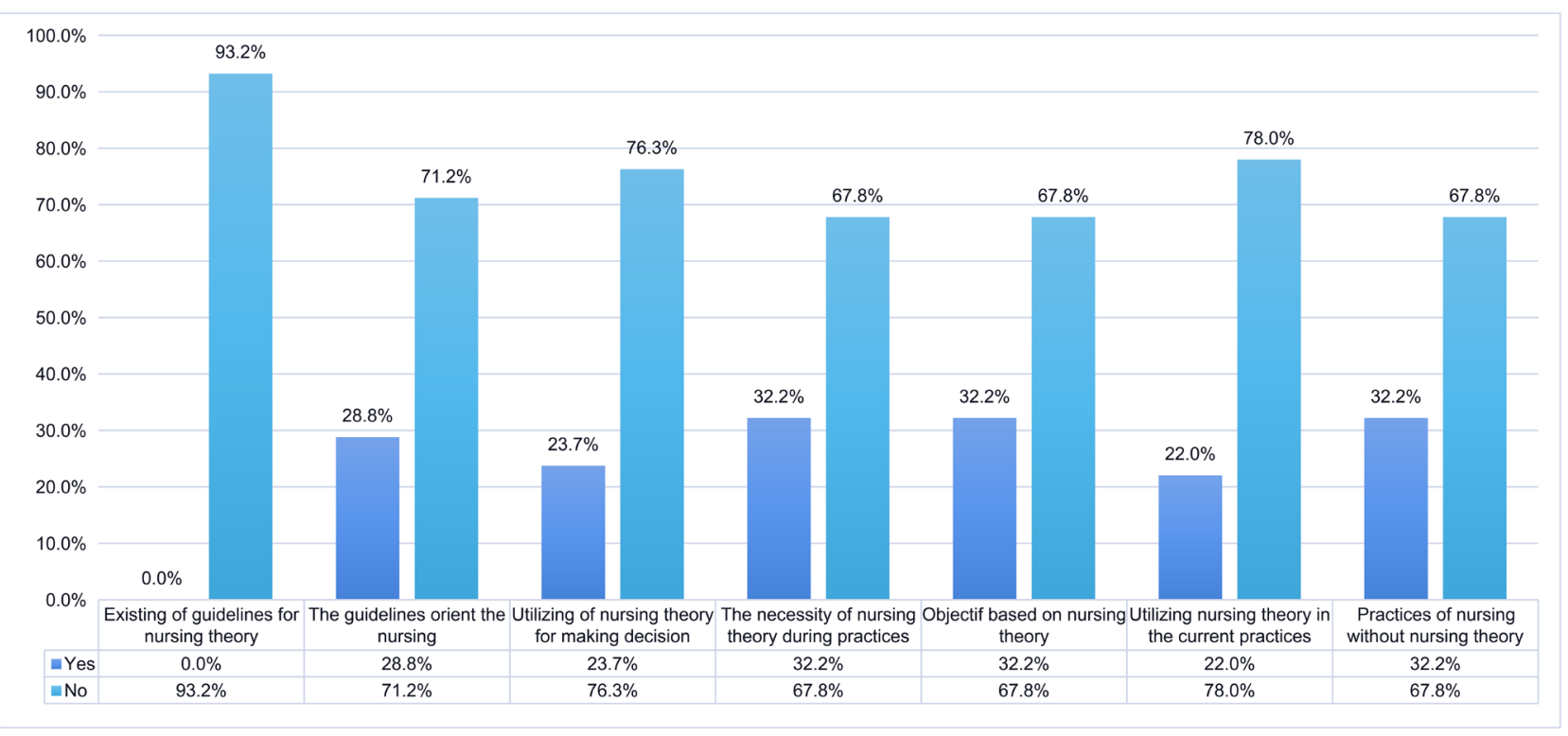

Figure 2. Baseline of nursing care.

Distribution of the Study Population according to Implementing Nursing Theory into Practices

The findings for the current study revealed that the participants knowledge was poor also during the implementation of nursing theory into practice as majority of them (83.1\%) assumed to not assess their patient condition by using various methods explained by the nursing theory and not using efficiency communication and interaction based on nursing theory; $72.9 \%$ do not Identify their patient needs based on nursing theory while $67.8 \%$ do not that nursing theory provide the basics of nursing practice (Table 4 ).

Distribution of the Study Population according to the Evaluation of the

\section{Patient's Condition}

Majority of the participants $(83.1 \%)$ could ignore the evaluation of the patient's condition according to the theoretical methods (Figure 3).

Distribution of the Study Population according to Rational Diagnosis of Nursing Theory

This study reaveled also a lack of knowledge on the steps of the rational diagnosis of nursing theory; whereby, for all variables' scores were less than $41 \%$ (Table 5).

\section{Discussion}

The study findings revealed that the age of participants ranged between 23years to 55 years $(\bar{x}=37.3)$. Majority of them were female $(60.5 \%)$ and $39.5 \%$ were man and majority of the participant were nurses who work at CHUK (56.8\%) and $43.2 \%$ were nurses who work at VNC (Table 2). This can be explained by the fact that CHUK is big public institution that host the faculty of medicine for medical students of the University of Burundi and serve as central reference level 
Table 4. Implementing nursing theory into practices.

\begin{tabular}{ccc}
\hline \multicolumn{1}{c}{ Characteristics } & & Frequency \\
\hline Assessment of patient status according to the theory methods & Yes & $16.9 \%$ \\
Identification of patient needs based on nursing theory & No & $83.1 \%$ \\
Efficiency and interaction communication based on nursing theory & Yes & $27.1 \%$ \\
& No & $72.9 \%$ \\
Nursing practices based on nursing theory & Yes & $32.2 \%$ \\
& No & $67.8 \%$ \\
\hline
\end{tabular}

Table 5. Rational diagnosis of nursing theory.

\begin{tabular}{ccc}
\hline Characteristics & & Frequency \\
\hline Improve nursing practice by influencing positively & Yes & $32.2 \%$ \\
the patient outcomes & No & $67.8 \%$ \\
Prioritization of nursing care based on nursing theory & Yes & $27.1 \%$ \\
Provide a rational nursing for reliable and valid data & No & $72.9 \%$ \\
collection on clients' situation & Yes & $27.1 \%$ \\
Use of nursing theory based on personal experience & No & $72.9 \%$ \\
& & Yes \\
\end{tabular}

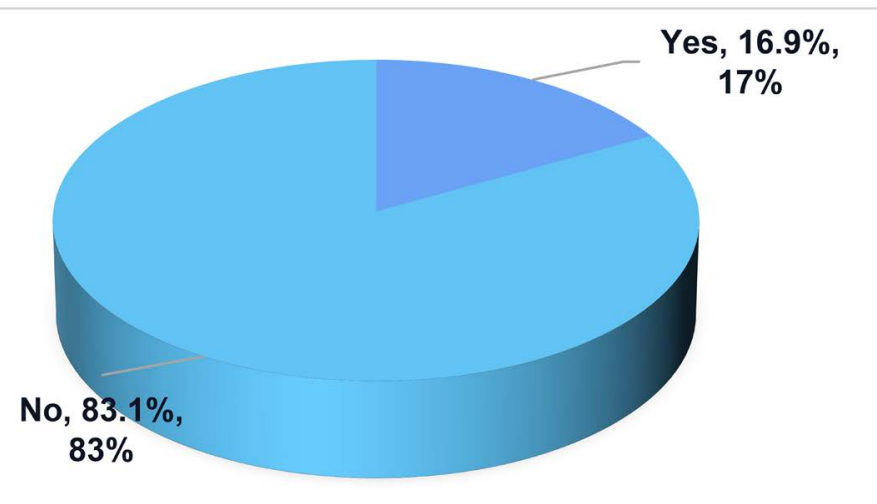

Figure 3. Evaluation of the patient's condition according to the theoretical methods.

while VNC is a private Free Methodist related institution that serves as a training center for students in the faculty of health sciences at Hope Africa University. Most of them (50.6\%) have been in service for 3 to 5 years, and majority of the participant $(53.1 \%)$ have secondary level of nursing training. This can be explained by the fact that previous skills in the country were oriented on the A2 level training, whilst the Bachelor and master degree were introduced in 2009 and 2012 respectively. Even though that these two HCFs are the center for training students at University level, most of the nurses who work there are nurses with A2 level. Therefore, these two levels (A2 and Bachelor) in these two HCFs are the first levels to be recognized and to explain the reason why nurses 
with master level exist at a small number. If the level of training could be considered as the parameter for implementing nursing theory in nursing practices, the A2 and bachelor nurses could be the first levels who are the principal to be considered. However, nursing practice depends totally on nurses' level of training according to the curriculum and their specialty. Even though that the master's level was not high represented in this study perhaps it could be considered as the principal level for recognizing the use of nursing theory. On the other hand, in Burundian nursing curriculum, there are no skills of nursing theory and its use into practice which are taught at secondary level (A2), which explain the fact why the findings of our study revealed a poor knowledge especially for nurses with A2 level in general. For implementing nursing theory into nursing practice, the government of Burundi could adopt a politic of closing the training of secondary level (A2) and help these nurses with secondary level to upgrade their knowledge with continuous training for bachelor level (Post-Basic Bachelor program). Lastly, this also reveals the need of Burundian's universities need to open more department of master program with varieties of specialties of advanced nursing practice to cover this gape into nursing practices and revise the bachelor level curriculum in term of using nursing theory in practice.

The participants' knowledge of nursing theory was significant poor, $24.1 \%$ were the only ones who know nursing theory while majority of them (75.9\%) did not have any idea of what is it (Figure 1). This can be explained by the above reason that most of participants were the A2 level nurse whose curriculum program does not include the use nursing theory in practice. In their study, Quinn \& McDonough, argued that by omitting nursing theory from, or failing to highlight its foundational role in nursing practice profession models contracts nursing as a unique discipline. Moreover, when science and theory do not appear to guide our nursing practice, we might risk to displaying only the art of nursing and being seen as task agents who move through patient care checking boxes instead of improving the lives of patients [13]. Therefore, for providing a patient centered-care base on scientific evidence, these nurses should develop their career by advancing their nursing skills and the government should organize a continuous in-service education system to allow them to continue their study. This will allow, especially these A2 level nurses to upgrade their nursing level where they will learn nursing theory and its importance at university level and be able to use this new skill in patient care.

The participants knowledge on the importance of nursing theory was significantly poor as for all variables, their scores were less than $34 \%$ (Table 3). This aline with the findings of the above variables of our study because most of our participants have no idea of what it is nursing theory. It's clear that they could not know its importance. The cause could be their nursing curriculum program that do not include the part of nursing theory in their training. For those with bachelor level, this could be explained by the institutional culture of not implementing these skills in their daily practice. This could cause harmful conse- 
quences on the health of the patient because the assumption of responsibility will not be satisfactory because the theory of nursing predicts, describes and explains a phenomenon before the nursing intervention [14].

Moreover, without knowledge of the fact it is difficult to follow up on the patient and to assess his evolution. Nursing theories help to recognize what should set the foundation of practice by explicitly describing nursing. Nursing theories provide the foundations of nursing practice; helps generate further knowledge, and indicate in which direction nursing should develop in the future [14]. By providing nurses a sense of identity, nursing theory can help patients, managers, and other healthcare professionals to acknowledge and understand the unique contribution that nurses make to the healthcare service. Nursing theories prepare the nurses to reflect on the assumptions and question the values in nursing. Theories are an important part of nursing and exist to improve patient care outcomes [14]. As a contribution, the Burundian government through the ministry of public health, could recommend to the institutions that have departments of nursing to review their curriculum planning and include the part that concerns nursing theories at all levels of study for future nurses to complete their studies with knowledge about the nursing theories which are the basis of nursing care.

The current study revealed also a lack of knowledge on the steps related to the baseline of nursing practice among the participant as for all variables the scores were less than $34 \%$, especialy that all participants disclaim to be guided by nursing theories during the implementation of nursing care. This could be explained by fact that the implementation of nursing theory in nursing practice in these two HCFs was still neglected. The arguments that justified this negligence of the underuse of the nursing theory were the lack of the use of guidelines during nursing theory in their services, lack of knowledge on the use and importance of nursing theory to guide them during the implementation of nursing practice, no use of nursing theory when making clinical judgement (Figure 2). This lack of knowledge on the steps related to the baseline of nursing practice could be explained by the lack of regular follow-up of the nurse managers during nursing practice. The consequences could be exposing the patients' health in danger as everyone could practice nursing as they understood it, which can lead to increase mortality and morbidity. Nursing theory should provide the principles that underpin practice and help to generate further nursing knowledge as nursing theory can guide nursing practice by giving a particular focus to nursing practice [15]. To overcome this challenge, we suggest that the authorities of the two HCFs may review the nursing guidelines and include those designed as a guide to nursing practice and organize continuing training related to nursing practice based on nursing theories to update the knowledge of their nurses.

The findings for the current study revealed that the participants knowledge was poor also during the implementation of nursing theory into practice as majority of them $(83.1 \%)$ assumed to not assess their patient condition by using various methods explained by the nursing theory and not using efficiency com- 
munication and interaction based on nursing theory; $72.9 \%$ do not Identify their patient needs based on nursing theory while $67.8 \%$ do not that nursing theory provide the basics of nursing practice (Table 4). This could be explained by the fact that these latter could not have any idea of what could be a nursing theory (75.9\%) (Figure 1) and did not know the importance of nursing theory (Table 3). Moreover, the cause could be also the lack of understanding the nursing process and the nursing care plan before the implementation of nursing interventions which will be dangerous to the patient's health and increase the patient's health care cost. Therefore, a continuous in-service system could the only way to overcome this challenge by enhancing these latter to advance their nursing skills.

Majority of the participants (83.1\%) could ignore the evaluation of the patient's condition according to the theoretical methods (Figure 3). This could be explained by the above reasons that these latter have a poor knowledge on the use of nursing theory. This study reaveled also a lack of knowledge on the steps of the rational diagnosis of nursing theory; whereby, for all variables' scores were less than $41 \%$ (Table 5). This means that the use of nursing theory in these two HCFs were neglected, not only by the ignorance, but also by lack of knowledge of its use on the implementation of evidence based scientifical nursing care. This concurs the findings of Randi where participants were emphasising that the use of knowledge was connected to their ability to get involved in and assessing particular situations so that their skills are integrating empirical phenomena into their existing knowledge framework [16]. Therefore, the University should focus on the use and importance of nursing care, so that these latter could implemetent it in their daily nursing practice. Moreover, the nursing management of these two HCFs, in collaboration with the top leaders of these institutions should make policy and ancourge nurses to implement their nursing practice based on this scientifical knowledge.

\section{Recommendation}

The authors have recommended in the current study the following:

1) The government through the ministry of health should implement the policy to allow, especially, these nurses with low level of education (A2) to upgrade their skills throughout continuous nursing education at university level so that they can have this skill of nursing theory which are considered at university level only.

2) Universities' institutions should open more departments of advanced nursing practice programs with varieties of specialties at Master or doctorate level to cover this gape into nursing practices and revise the bachelor level curriculum in terms of using nursing theory in practice.

3) The Institutional leaders of these two HCFs should set out a framework for monitoring and evaluating compliance with guidelines related to the use of nursing theories in their daily nursing practices in terms of delivering safe and reliable nursing care. 


\section{Conclusion}

The study findings revealed a poor knowledge among the participants as for all figures that concern the parameters of the importance of nursing theory, the guidance of nursing theory, the application of nursing theory to nursing practice, the rational diagnosis of nursing theory that verified the hypothesis of this study revealed that nurses of the two HCFs neglected and underused nursing theories in their nursing practice as they scored almost $24.1 \%$ while those who had no idea related to the nursing theory reach a percentage of $75.9 \%$.

\section{Limitation}

In our study, the limitations were that it was conducted in two hospitals among the 5 of the one District in which the study was conducted, while the city of $\mathrm{Bu}$ jumbura has 3 districts. Authors did not test the reliability and validity of the questionnaire.

\section{Conflicts of Interest}

The authors declare no conflicts of interest regarding the publication of this paper.

\section{References}

[1] McDonald, A. (2016) The Importance of Nursing Theory. https://www.bartleby.com/essay/The-Importance-Of-Theory-Of-Nursing-P3BAX4 LJPL95

[2] Arora, S. (2015) Integration of Nursing Theories in Practice. International Journal of Nursing Science Practice and Research, 1, 8-12.

https://www.researchgate.net/publication/283319003_Integration_of_Nursing_The ories_in_Practice

[3] Saleh, U.S. (2018) Theory Guided Practice in Nursing. Journal of Nursing Research and Practice, 2, 18.

https://www.pulsus.com/scholarly-articles/theory-guided-practice-in-nursing-4140. html

[4] OECD (2010) Improving Value in Health Care: Measuring Quality: OECD Publishing.

https://www.oecd-ilibrary.org/social-issues-migration-health/improving-value-in-h ealth-care_9789264094819-en

[5] Kamau S.M., Rotich, R.J., Cheruiyot, B.C. and Ng’eno, L.C. (2015) Applying Florence Nightingale's Model of Nursing and the Environment on Multiple Drug Resistant Tuberculosis Infected Patients in the Kenyan Setting. Open Access Library Journal, 2, e1796.

https://www.academia.edu/17235450/Applying_Florence_Nightingale_s_Model_of_ Nurs-

ing_and_the_Environment_on_Multiple_Drug_Resistant_Tuberculosis_Infected_P atients_in_the_Kenyan_Setting

[6] Owino, J., Legault, F., Mumbo, H.M., Odera, O. and Ayugi, M.E.A (2013) Grounded Theory Study for Antenatal Care in Kenya. European Scientific Journal, 9, 229-238. https://core.ac.uk/download/pdf/328023814.pdf 
[7] Taylor, C., Lillis, C., Lynn, P. and LeMone, P. (2015) Fundamentals of Nursing: The Art and Science of Person-Centered Nursing Care. 8th Edition, Wolters Kluwer Health, Philadelphia.

https://www.worldcat.org/title/fundamentals-of-nursing-the-art-and-science-of-per son-centered-nursing-care/oclc/967651465

[8] Masters, K. (2014) Nursing Theories: A framework For Professional Practice. 2nd edition. Jones \& Bartlett Learning, Burlington, USA.

https://www.amazon.com/Nursing-Theories-Framework-Professional-Practice/dp/ 1284048357

[9] George, J.B. (2011) Nursing Theories: The Base for Professional Nursing Practice. 5th Edition, Prentice Hall, New Jersey.

https://www.pearson.com/us/higher-education/program/George-Nursing-TheoriesThe-Base-for-Professional-Nursing-Practice-6th-Edition/PGM122432.html

[10] Haapoja, A. (2014) The Nursing Process, a Tool to Enhance Clinical Care-a Theoretical study. https://core.ac.uk/download/pdf/38105708.pdf

[11] Jackson, J. (2012) Nursing Paradigms and Theories. https://sigma.nursingrepository.org/bitstream/handle/10755/338888/Nursing+Para digms+and+Theories, $+\mathrm{A}+$ Primer.pdf? sequence $=1$

[12] Martinsen, H.E. (2011) Care for Nurses Only? Medicine and the Perceiving Eye. Health Care Analysis, 19, 15-27. https://doi.org/10.1007/s10728-010-0161-9 https://link.springer.com/article/10.1007/s10728-010-0161-9

[13] Quinn, B. and McDonough, A. (2019) Nursing Theory in Hospital Models of Care. American Journal of Nursing, 119, $11 \mathrm{p}$. https://doi.org/10.1097/01.NAJ.0000615708.01269.21 https://journals.lww.com/ajnonline/fulltext/2019/12000/nursing_theory_in_hospital _models_of_care.5.aspx

[14] Lee, S.W. (2013) Overview of Nursing Theory. Nursing Science Research, 12, 58-67. https://www.oita-nhs.ac.jp/journal/PDF/12_2/12_2_3.pdf

[15] Sarah, C. (2017) Nursing theory: Its Importance to Practice. Nursing Standard, 17, 33-37.

https://journals.rcni.com/nursing-standard/nursing-theory-its-importance-to-pract ice-ns2003.07.17.46.33.c3425\#: :text

The\%20importance\%20of\%20nursing\%20theory\&text

The\%20benefits\%20of\%20having\%20a,and\%20education\%20(Nolan\%201996).

[16] Randi, S. (2009) Knowledge Use in Nursing Practice: The Importance of Practical Understanding and Personal Involvement. Nurse Education Today, 30, 132-136. https://doi.org/10.1016/j.nedt.2009.06.012 https://www.researchgate.net/publication/26694594_Knowledge_use_in_nursing_p ractice_The_importance_of_practical_understanding_and_personal_involvement 


\section{Appendices: Questionnaire}

\section{Demographic data}

1) Age

2) Sex: Male $\square$ Female

3) Hospital

- Van Norman Clinic (VNC)

- University' Hospital Centre of Kamenge (CHUK)

4) Length or period on service

a) 1 - 2 years $\square$

b) 3 - 5 years $\square$

c) 6 - 10 years $\square$

d) More than 10 years

5) Level of education

a) Diploma (A2)

b) Bachelor degree $\square$

c) Masters degree $\square$

6) Department

a) Surgical unit $\square$

b) Maternity Unit

c) Internal medicine Unity

d) Emergency Unity

e) Paediatric Unit $\square$

\section{A. IMPORTANCE OF NURSING THEORY}

7) Do you know the nursing theory? YES $\square$ NO

8) Does nursing theory describe, predict and explain phenomenon? YES $\square$ NO $\square$

9) Do you know the importance of nursing theory during nursing care practices? YES $\square$ NO

10)Do theories help nurses to decide what they know and what they need to know? YES $\square$ NO

11)Should theories provide fundamentals of nursing practice? YES $\square$ NO $\square$

12)Do theories help to distinguish what should form the basis of practice by explicitly describing nursing? YES $\square$ NO $\square$

13)Do the nursing theories help to generate more new knowledge in nursing? YES $\square$ NO $\square$

14)Is it difficult to provide nursing care without nursing theories? YES $\square$ NO $\square$

\section{B. BASELINE OF NURSING THEORY}


15)Do you have guidelines of the use of nursing theory in your services? YES $\square$ NO $\square$

16)Do you need nursing theories to guide your orientation during the implementation of nursing care? YES $\square$ NO $\square$

17)Do you use nursing theories when taking clinical decision for the patient? YES $\square$ NO $\square$

18)Do you think that nursing theories are needed during nursing practice? YES $\square$ NO $\square$

19)Does the nursing theory help nurses to understand their purpose and role in the healthcare environment? YES $\square$ NO $\square$

20)Do you use nursing theories in your daily care? YES $\square$ NO

21)Is nursing care badly led when nursing theories are not used in nursing? YES $\square$ NO $\square$

C. IMPLEMENTING NURSING THEORY INTO NURSING PRACTICE

22)In your health care facility, do you assess the patient condition by the various methods explained by the nursing theory?

YES $\square$ NO $\square$

23)Do you identify the needs of the patient by using the theory before administering care? YES $\square$ NO $\square$

24)Do you use an effective communication and interaction with the patient and his family in decision-making? YES $\square$ NO $\square$

25)Should nursing theory provide the basics of practice? YES $\square$ NO $\square$

D. RATIONAL DIAGNOSIS OF NURSING THEORY

26) The main goal of the theory of the nursing profession is to improve practice by positively influencing health and quality of life of patients? YES $\square$ NO $\square$

27)Do you agree that systematic and targeted care requires that the practice is based on theory?

YES $\square$ NO $\square$

28)Is Theoretical Nursing Practice providing a rational for collecting reliable and valid data about sanitary situation of clients? YES $\square$ NO $\square$

29)Is it necessary to use nursing theories when you have a great experience in nursing care?

YES $\square \mathrm{NO} \square$ 